\title{
Multi-Input Intervention Analysis for Evaluating of the Domestic Airline Passengers in an International Airport
}

\author{
Salam Ali Wiradinata ${ }^{1, *}$, Rado Yendra ${ }^{2}$, Suhartono $^{3}$, Moh Danil Hendry Gamal ${ }^{1}$ \\ ${ }^{1}$ Department of Mathematics, University of Riau, Pekanbaru, Indonesia \\ ${ }^{2}$ Department of Mathematics, State Islamic University of Sultan Syarif Kasim, Pekanbaru, Indonesia \\ ${ }^{3}$ Department of Statistics, Institut Teknologi Sepuluh Nopember, Surabaya, Indonesia
}

Email address:

salam.ali7893@unri.ac.id (S. A. Wiradinata),yendra_75@yahoo.com.sg (R. Yendra), suhartono@statistika.its.ac.id (Suhartono), mdhgamal@unri.ac.id (M. D. H. Gamal)

${ }^{*}$ Corresponding author

\section{To cite this article:}

Salam Ali Wiradinata, Rado Yendra, Suhartono, Moh Danil Hendry Gamal. Multi-Input Intervention Analysis for Evaluating of the Domestic Airline Passengers in an International Airport. Science Journal of Applied Mathematics and Statistics.

Vol. 5, No. 3, 2017, pp. 110-126. doi: 10.11648/j.sjams.20170503.13

Received: April 5, 2017; Accepted: April 18, 2017; Published: June 3, 2017

\begin{abstract}
This article discusses multi-input intervention analysis to investigate the effect of interventions which may come from internal and/or external factors in time series data. The objective of this research is to obtain multi-input intervention analysis, which can explain the magnitude and periodic of each event effected to monthly types of the domestic airline passenger flight in Pekanbaru airport. The purpose of this study is to give a theoretical and empirical studies on the multi-input intervention analysis, particularly to develop and construct a model procedure of multi-input intervention cused by pulse and/or step function to evaluate the impact of these external and/or internal events in time series data. Monthly data comprising the number of the domestic airline passenger flight in Pekanbaru airport are used as the data for this case study. Generally, the forest fires, peatland, and illegal burning in Riau Province give a negative permanent impacts after four months. This study focuses on the derivation of some effect shapes, i.e. the temporary, gradually or permanent monthly airline passenger. In addition, the research also discusses how to assess the effect of an intervention in transformation data.
\end{abstract}

Keywords: Time Series Data, Multi-input Intervention Analysis, Pulse Function, Step Function

\section{Introduction}

Quantitative models on autoregressive integrated moving average or better known as ARIMA were developed in 1976 by Box and Jenkins in full as a standard procedure in the modeling of time series analysis. In the development of time series analysis, the various phenomena of interest and not simply have been often the linkages with the relationship between variables in a time series data. Statistical modeling of time series analysis in its development presents the ARIMA model that is a popular model and widely applied in modeling and forecasting time series data. Based on BoxJenkins procedure which is standard procedure aims to obtain an appropriate ARIMA model to a time series data. This procedure consists of four stages, namely the identification, parameter estimation and tests of significance, and check the diagnosis and forecasting. At the identification stage, this procedure requires the fulfillment of stationary conditions on the average value of the mean and variance of time series data.

Based on the fact that real time data on the time series data, it is often encountered the problem of data that are changing the pattern of the mean extreme or known by the regime change/structural changes [13, p. 274]. These changes are usually caused by the presence of an intervention coming from external factors and/or internal. The pattern of extreme data changed frequently in incorrect results has implications for the identification stage obtaining spurious or counterfeit final model for a time series data.

Disaster is one form of intervention of external factors which often impact on the changing pattern of the data in a time series. In general, the disaster that occurred in an area 
can be divided into two kinds, namely natural disasters (natural-made) and man-made disasters (man-made). Some examples of natural disasters that have occurred in Riau Province is catastrophic smog from forest fires, soil (peat) and/or because of the impact of the spread of smoke of forest fires neighboring provinces such as Jambi and South Sumatra carried on the wind to Riau province, smoke appears as a result of uncontrolled burning of the continued cultivation of plantation and having an impact on several areas in Southeast Asia such as Malaysia and Singapore, especially in the Province of Riau. While examples of man-made disasters are the bomb and raw shoot in Jakarta in January 14, 2016 in front of Sarinah Building, Jakarta bombing in July 17, 2009, Bali bombings in October 12, 2002 and in October 1, 2005.

One of the important issues of the catastrophic events is how to measure or construct a mathematical model, the magnitude and duration, the impact caused by the intervention of various disasters. For example, how to measure and determine the impact of disasters smoke haze from forest fires and smoke pollution in Southeast Asia in 2013 to the field of air transport for domestic flights via International Airport Sultan Syarif Kasim II Pekanbaru, as measured by the number of passengers types of domestic flights to Riau Province. The same question also appears how the construction of a mathematical equation or model of forecasting are affected by natural disasters to the number of passengers types of domestic flights to Riau Province. One statistical method that can address the concerns and questions is the analysis of multi-input intervention.

In the last few years there is a lot of research on the analysis of interventions that have been conducted to evaluate the effects of an internal and/or external intervention. Until now, most research on the analysis of interventions relates to the evaluation of the impact of new policies on an applied field. The subject of further analysis of the intervention can be found in several books of time series analysis, among others are Brockwell and Davis [3, p. 340], Box et al. [5, p. 481], Cryer and Chan [11, p. 249], Drakos and Kutan [12], Luthkepohl [22, p. 604], Enders [13, p. 280], Hamilton [16, p. 677], Montgomery et al. [26, p. 330], Tsay [35, p. 389], Wei [39, p. 212], Yaffee and McGee [41, p. 265]. One of the main problems in the modeling analysis of the intervention is the absence of a standard procedure for the establishment of a model of intervention, either in a single intervention or multiple interventions (more than one type of intervention). In addition, most of the discussion of intervention analysis on a variety of time series analysis reference books covers the analysis of a single intervention.

Various studies on the intervention model are not only limited to the analysis of a single intervention (single-input), the step function or pulse only, but also series of data. They can contain more than one type of intervention (multi-input), i.e. step and pulse function. So it is still very in need to be further developed the standard procedures in modeling the multi-input intervention. These problems provide further opportunities to do research related to the multi-input intervention, namely this research is applied to model and forecast the monthly data types of the number of passengers for domestic flights in Riau Province.

Intervention model was first proposed by Box and Tiao [6] who examine the effect of the enactment of legislation on the engine design oxidant levels of pollution in the Los Angeles area. Then Ladolter and Chan [24] use the intervention analysis in response to changes in federal policy to study and evaluate the effect of raising the speed limit on the interstate highway system countryside to 65 miles per hour (mph), higher speeds are generally considered to generate economic benefits primarily because of the reduction in travel time. However, higher speeds are also associated with the increased risk of accidents.

Many different models have been proposed for multi-input intervention time series forecasting by researchers. Rezeki et al. [34] use the multi-input intervention analysis model to analyze and evaluate the impact of the Asian crisis and the terrorist attacks against tourist arrivals in Bali. The study concludes that in general the Asian crisis and the Bali bombings a negative impact on the number of tourist arrivals in Bali. This is confirmed by the results of the study the number of tourists to Bali when there are permanent events effects of the Asian crisis after a delay of 10 months as well as the Bali bombing I and II that have a direct impact and temporary.

Lee et al. [25] model using multi-input interventions to evaluate the effects of the Asian crisis and the terrorist attacks against the number of tourist arrivals. The results of empirical studies on these case studies show that the multiinput intervention model is proven to explain precisely the magnitude and duration of the impact of disasters on a time series data.

The facts in these studies underlie the implementation of further study forecasting in the field of air transport. The problems of intervention analysis of multi-input evaluates the number of passengers types of domestic flights in Riau Province with a focus on the development of forecasting models of intervention multi-input capable of explaining the period and the magnitude of the impact these events. In this research we discuss the results of theoretical and empirical studies on the development of procedures for establishing a multi-input intervention model used for the evaluation of the impact of a disaster on a time series data. Theoretical study is focused on the identification stage, namely the decrease in the quantities of the statistics used as the basis for determining the order of the intervention model. Furthermore, the results of a theoretical study are used as a basis to develop a standard procedure for the establishment of a multi-input intervention model. At the end, the empirical studies are conducted to analyze the issue, which is still in a question in evaluating the impact of disasters on a real case occurred in the province of Riau, namely the impact of disasters smoke haze from forest fires in the last five years, Southeast Asia pollution smoke in 2013, and the national elections as a political year in July 2014, to the number of domestic passengers flying in Riau Province. 


\section{General Multi-input Intervention Model}

A time series data can be affected by a variety of special events, namely the existence of an intervention either internal or external that can cause changes in the pattern of time series data. In the analysis of the intervention, it is assumed that the incidence of intervention occurs at time $t$ is known as a time series.

In the intervention model, a shock or series of interventions called discrete input is valuable, while the time series data to model referred to as the series output. With the intervention model, it can be seen how big and long the effects of intervention events. The process of estimating the effect of intervention is called the analysis of the intervention (intervention or interrupted) time series. Time series data in several empirical studies often consist of the observations of the several intervention variables.

A general formula is formed if there is more than one type of intervention occurs in a time series data, then the model suitable for use is a multi-input intervention model whose mathematical model is given as follows (see Abraham [1], Box et al. [5, p. 482], Box and Tiao [6], Ismail et al. [19], Montgomery and Weatherby [29], Wei [39, p. 215])

$$
Y_{t}=\sum_{j=1}^{k} \frac{\omega_{s_{j}}(B) B^{b_{j}}}{\delta_{r_{j}}(B)} \zeta_{j_{t}}+\frac{\theta_{q}(B) \Theta_{Q}\left(B^{S}\right)}{\varphi_{p}(B) \Phi_{P}\left(B^{S}\right)(1-B)^{d}\left(1-B^{S}\right)^{D}} a_{t}
$$

where a polynomial form of intervention model parameters contained in the response is defined as $\omega_{s_{j}}(B)=\omega_{0_{j}}-\ldots-\omega_{s_{j}} B^{s}, \delta_{r_{j}}(B)=\delta_{0_{j}}-\ldots-\delta_{r_{j}} B^{r}$, while $Y_{t}$ is a response variable at time $t, \zeta_{j_{t}}$ is a binary indicator varible that shows the existance of an intervention at time $t$ and for the $j$ th with respect to the intervention variable at time $t$ and $\zeta_{j_{t}}$ is a deterministic indicator variable, taking only the values 0 and 1 to indicate nonoccurrence and occurrence of some event respectively which indicates whether there is influence of intervention at time $t$, and $b$ is the delay time from the effects of an intervention, to the declared the value of $\omega_{s_{j}}(B)$ a parameter models intervention $j$ th the specified order-s, while the value $\delta_{r_{j}}$ is stated parameters intervention model $j$ th the specified order$r, \theta_{q}(B)$ and $\varphi_{p}(B)$ are moving average and autoregressive polynomials in $B$ of degrees $q$ and $p$, respectively. The roots of $\theta_{q}(B)$ lie outside and $\varphi_{p}(B)$ lie in or outside the unit circle.

In order to identify the model of intervention $b, r$ and $s$ can be done by looking at the residual plots. Residual value to be obtained from the difference between the observed data values uses noise forecasting models. Suppose residual denote as follows:

$$
Y_{t}^{*}=Y_{t}-n_{t}=f\left(\zeta_{t}\right)
$$

Values $s$ indicate when the motion of response weight began to decline, the value of $b$ is determined by looking at when the effect of the intervention started happening while $r$ is the pattern of the residuals. Theoretical and complete study can be seen in Lee et al. [25], Helfenstein [18] and Makridakis et al [30].

Thre are two common types of deterministic input variable $\zeta_{j_{t}}$ that have been found useful to represent the impact of intervention events on a time series. Both of these are indicator variables taking only the values 0 and 1 to denote the nonoccurrence and occurrence of intervention. One type is a step function at time $T$, given by $[5$, p. $530 ; 26$, p. 462 ; 39 , p. 213] as

$$
\xi_{t}=S_{t}^{(T)}= \begin{cases}0, & t<T \\ 1, & t \geq T\end{cases}
$$

typically used to represent the effects of an intervention that are expected to remain permanent after time $\mathrm{T}$ to some extent. The other type is a pulse function at $\mathrm{T}$, given by $[5, \mathrm{p}$. $530 ; 26$, p. $462 ; 39$, p. 213] as

$$
\xi_{t}=P_{t}^{(T)}= \begin{cases}0, & t \neq T \\ 1, & t=T\end{cases}
$$

that represents the effects of an intervention that are temporary or transient and will die out after time $T$. These indicator input variables are used in many situations where the effects of the intervention cannot be represented as the response to a quantitative variable that does not exist or it is impractical or impossible to obtain the measurements of such a variable.

\subsection{Case 1 Model}

Multi-input intervention model with a step function $\left(b_{1}=\right.$ $\left.1, r_{1}=1, s_{1}=1\right)$ and followed by a pulse function with $\left(b_{2}=\right.$ $\left.1, r_{2}=0, s_{2}=1\right)$ is given as

$$
Y_{t}=\frac{\left(\omega_{0_{1}}-\omega_{1_{1}} B\right) B^{1}}{1-\delta_{1_{1}} B} S_{t}+\left[\left(\omega_{0_{2}}-\omega_{1_{2}} B\right) B^{1}\right] P_{t}+N_{t},
$$

where

$$
N_{t}=\frac{\theta_{q}(B)}{\varphi_{p}(B)(1-B)^{d}\left(1-B^{S}\right)^{D}} a_{t} \text { and } \quad\left|\delta_{1_{1}}\right|<1 \quad \text { so that }
$$

intervention effects that occur are

$$
Y_{t}^{*}=\omega_{0_{1}} S_{t-1}+\left(\omega_{0_{1}} \delta_{1_{1}}-\omega_{1_{1}}\right) S_{t-2}+\delta_{1_{1}}\left(\omega_{0_{1}} \delta_{1_{1}}-\omega_{1_{1}}\right) S_{t-3}+\ldots+\delta_{1_{1}}{ }^{k-2}\left(\omega_{0_{1}} \delta_{1_{1}}-\omega_{1_{1}}\right) S_{t-k}+\omega_{0_{2}} P_{t-1}-\omega_{1_{2}} P_{t-2},
$$

which can also be written in Table 1 . 
Table 1. Magnitude of the Effects Intervention.

\begin{tabular}{lll}
\hline Response & Effect's Magnitude & Time \\
\hline 0 & & \\
& $\omega_{0_{1}}$ & $t \leq T_{1}$ \\
& $\omega_{0_{1}}+\sum_{j=0}^{k-2} \delta_{1_{1}}^{j}\left(\omega_{0_{1}} \delta_{1_{1}}-\omega_{1_{1}}\right)$ & $t=T_{1}+1$ \\
& & $t=T_{1}+k$ \\
$Y_{\mathrm{t}}^{*}=$ & $T_{1}+k \leq T_{2}$ \\
& $\omega_{0_{1}}+\sum_{j=0}^{k-2} \delta_{1_{1}}^{j}\left(\omega_{0_{1}} \delta_{1_{1}}-\omega_{1_{1}}\right)+\omega_{0_{2}}$ & $t \geq T_{2}+3$ \\
& $\omega_{0_{1}}+\sum_{j=0}^{k-2} \delta_{1_{1}}^{j}\left(\omega_{01} \delta_{1_{1}}-\omega_{1_{1}}\right)+\omega_{0_{2}}-\omega_{1_{2}}$ & $t=T_{2}+2$ \\
& with $k=2,3, \ldots$ & \\
\hline
\end{tabular}

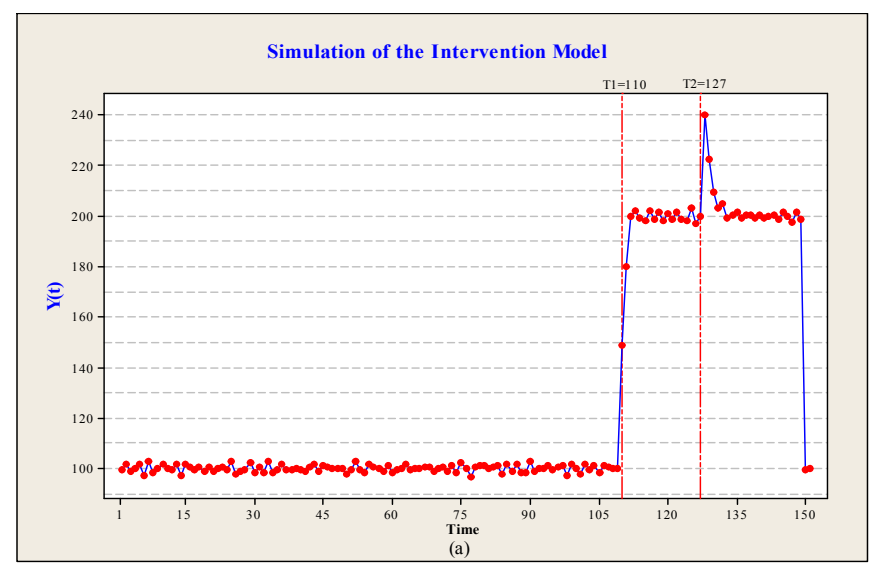

The illustration of Eq. (6) and its impact are represented in Figure 1. For illustrations, consider a multi-input intervention with two events, namely a step function occurring at $t=T_{1}=$ 110 where $\omega_{0_{1}}=50, \omega_{1_{1}}=-30, \delta_{1_{2}}=0,8, \omega_{0_{2}}=-20$, $\omega_{1_{2}}=5$ and $\omega_{2_{1}}=4$ with $\left(b_{1}=1, s_{1}=2, r_{1}=0\right)$ which is followed by a pulse function at $t=T_{2}=127$ with $\left(b_{2}=1, r_{2}=\right.$ $\left.1, s_{2}=1\right)$. The first intervention that affected the data at $t$ $=111$, with a magnitude of 50 . The pulse function intervention had an effect that lasted for 3 periods beyond $t=$ $T_{1}=110$ with a magnitude effect of -35 and -40 on the second and third after the intervention, respectively.

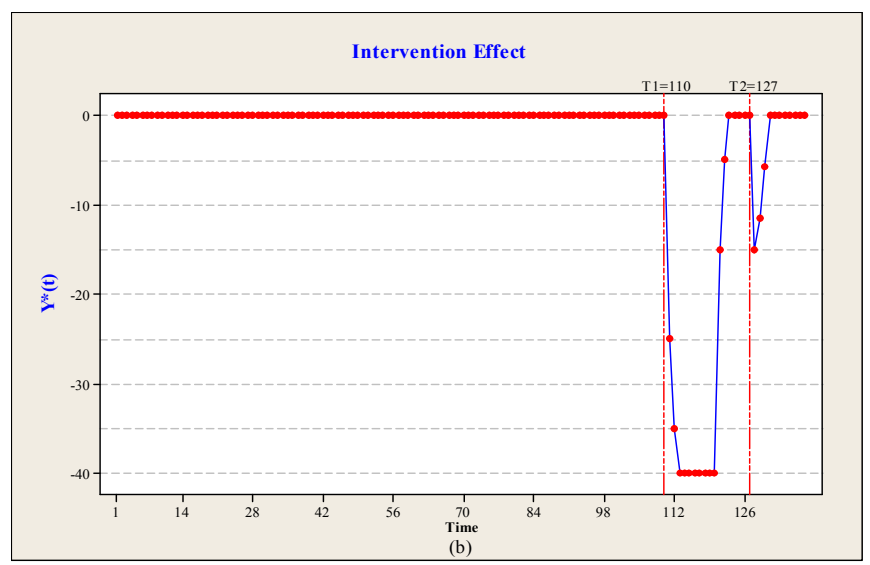

Figure 1. (a) Plot of Simulation the Intervention Model, (b) Intervention Effect of the Multi Input Intervention where the Step Function ( $\left.b_{1}=1, s_{1}=2, r_{1}=0\right)$ Occurred at $T_{1}=110$ and Followed by the Pulse Function $\left(b_{2}=1, r_{2}=1, s_{2}=1\right)$ at $T_{2}=127$.

Figure 1 shows the simulation study used to show that the response function to estimate the order of a multi-input intervention model to do exactly the kind of data of the number of passengers for domestic flights in Pekanbaru airport. In Figure 1 (a) it can be seen that the data are stable at 100 from $t$ $=1$ to $t=101$ rising at $t=150,180$ and 200 to $t=131$ and rising again to 240 at $t=132$ and slowly or gradually falling back to the value of 200 . While $Y_{\mathrm{t}}$ shows data of simulation

$$
Y_{t}=\left[\left(\omega_{0_{1}}-\omega_{1_{1}} B-\omega_{2_{1}} B^{2}\right) B^{1}\right] P_{1, t}+\frac{\left(\omega_{0_{2}}-\omega_{1_{2}} B\right) B^{1}}{1-\delta_{1_{2}} B} S_{2, t}+N_{t},
$$

where $\left|\delta_{1_{2}}\right|<1$, so that intervention effects that occur are

$$
Y_{t}^{*}=\omega_{0_{1}} P_{1, t-1}-\omega_{1_{1}} P_{1, t-2}-\omega_{2_{1}} P_{1, t-3}+\omega_{0_{2}} S_{2, t-1}+\left(\omega_{0_{2}} \delta_{1_{2}}-\omega_{1_{2}}\right) S_{2, t-2}+\left(\omega_{0_{2}} \delta_{1_{2}}-\omega_{1_{2}}\right) \delta_{1_{2}} S_{2, t-3}+\ldots
$$

which can also be written in Table 2 .

Table 2. Magnitude of the Effects Intervention.

\begin{tabular}{lll}
\hline Response & Effect's Magnitude & Time \\
\hline & 0 & $t \leq T_{1}$ \\
& $\omega_{0_{1}}$ & $t=T_{1}+1$ \\
& $-\omega_{1_{1}}$ & $t=T_{1}+2$ \\
$Y_{\mathrm{t}}^{*}=$ & $-\omega_{2_{1}}$ & $t=T_{1}+3$ \\
& 0 & $t=T_{1}+k \leq T_{2}, k \geq 4$ \\
& $\omega_{0_{2}} \sum_{i=1}^{m} \delta_{1_{2}}^{i-1}-\omega_{1_{2}} \sum_{i=2}^{m} \delta_{1_{2}}^{i-2}$ & $t \geq T_{2}+m, \quad m \geq 1$ \\
& with $k=2,3, \ldots$ &
\end{tabular}

Figure 2 shows the simulation considering a multi-input intervention with two events, namely a step function occurring at $T_{1}=110$ assuming step function $\left(b_{1}=1, s_{1}=2, r_{1}\right.$ $=0$ ) the initial value for $\omega_{0_{1}}=100, \omega_{1_{1}}=-60, \delta=0,5$, $\omega_{0_{2}}=-40, \omega_{1_{2}}=5$ and $\omega_{2_{1}}=4$, which is followed by a pulse function $\left(b_{2}=1, r_{2}=1, s_{2}=1\right)$ occurred at $t=T_{2}=127$. 

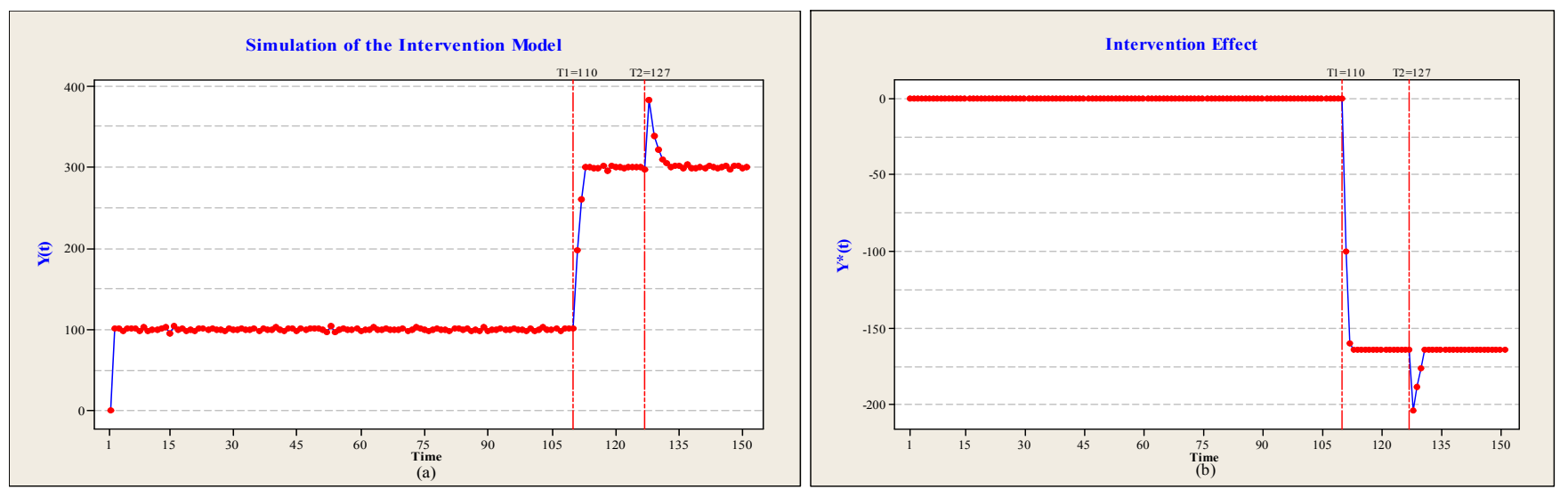

Figure 2. (a) Plot of Simulation the Intervention model, (b) Intervention Effect of the Multi-Input Intervention where the Step Function ( $\left.b_{1}=1, s_{1}=2, r_{1}=0\right)$ Occurred at $T_{1}=110$ and Followed by the Pulse Function $\left(b_{2}=1, r_{2}=1, s_{2}=1\right)$ at $T_{2}=127$.

From Figure 2 (a) it is shown that the data is stable at 100 from $t=2$ until $t=110$ increasing at $t=111,113$ and 114 still $t=116$ and stable in value at 300 then rising again to 380 at $t$ $=127$ and gradually or permanent effect at 300 .

\section{Parameter Estimation}

The intervention model is defined as [33, p. 332]

$$
Y_{t}=\frac{\omega_{s}(B)}{\delta_{r}(B)} \xi_{t-b}+\frac{\theta_{q}(B)}{\varphi_{p}(B)(1-B)^{d}\left(1-B^{S}\right)^{D}} a_{t},
$$

Eq.(9) can be rewritten as

$\delta_{r}(B) \varphi_{p}(B)(1-B)^{d} Y_{t}=\omega_{s}(B) \varphi_{p}(B)(1-B)^{d} \xi_{t-b}+\delta_{r}(B) \theta_{q}(B) a_{t}$ and $/$ or

$$
c(B) Y_{t}=d(B) \xi_{t-b}+e(B) a_{t},
$$

where

$$
\begin{gathered}
c(B)=\delta_{r}(B) \varphi_{p}(B)(1-B)^{d}\left(1-B^{S}\right)^{D}=1-c_{1} B-\ldots-c_{p+r} B^{p+r} \\
d(B)=\omega_{s}(B) \varphi_{p}(B)(1-B)^{d}\left(1-B^{S}\right)^{D}=d_{0}-\ldots-d_{p+s} B^{p+s} \\
e(B)=\delta_{r}(B) \theta_{q}(B)=1-\ldots-e_{r+q} B^{r+q}
\end{gathered}
$$

and thus,

$$
a_{t}=Y_{t}-c_{1} Y_{t-1}-\ldots-c_{p+r} Y_{t-p-r}-d_{0} \xi_{t-b}-\ldots-d_{p+s} \xi_{t-b-p-s}+e_{1} a_{t-1}-\ldots-e_{r+q} a_{t-r-q},
$$

and can be represented as:

$$
a_{t}=\frac{c(B) Y_{t}-d(B) \xi_{t-b}}{e(B)}
$$

under the assumption that the $a_{t}$ are $N\left(0, \sigma_{a}^{2}\right)$ white noise, conditional likelihood function

$$
L\left(\delta, \omega, \varphi, \theta, \sigma_{a}^{2} \mid b, \xi, Y, \xi_{0}, Y_{0}, a_{0}\right)=\left(2 \pi \sigma_{a}^{2}\right)^{-n / 2} \exp \left[-\frac{1}{2 \sigma_{a}^{2}} \sum_{t=1}^{n} a_{t}^{2}\right]
$$

In general, the estimation methods introduced in $[39, \mathrm{p}$. 145] can also be used to estimate the parameters $\delta, \omega, \varphi, \theta$ and $\sigma_{a}^{2}$. For example, by setting the unknown $a$ 's equal to their conditional expected values of zero, the nonlinear least squares estimate of these parameters is obtained by minimizing

$$
L(\delta, \omega, \varphi, \theta \mid b)=\sum_{t=t_{0}}^{n} a_{t}^{2}
$$


where $t_{0}=\max \{p+r+1, b+p+s+1\}$ and $a_{t}$ are the residuals under the white noise assumption and normal distribution.

\section{Research Methodology}

The intervention response or $Y_{t}^{*}$ is easily formulated using the response values chart for determining the order of the intervention model using the orders $b, s$ and $r$.

The intervention response denoted as $Y_{t}^{*}$ is basically residual or error which is the difference between the actual data and the ARIMA model forecasts based on the data before the intervention. A complete procedure of the intervention model building can be used to evaluate these $\mathrm{k}$ intervention functions at time $T_{1}, T_{2}, \ldots, T_{\mathrm{k}}$ as according to the following procedures. This procedure is described in Ismail et al. [19], Lee et al. [25], Montgomery et al. [26, p. 309], Yaffee and McGee [41, p. 282].

The First Procedure:

Dividing the data set of time series into $(k+1)$ parts

a Part 1:

The first part is the data before the first intervention, as many as $n_{0_{t}}$ time periods, i.e. $t=1,2, \cdots, T_{1}-1$. Denoted the data as $Y_{0_{t}}$.

b Part 2:

The second part is the data from the first intervention until just before the second intervention, as many as $n_{1_{t}}$ time periods, i.e. $t=T_{1}, T_{1}+1, T_{1}+2, \ldots, T_{2}-1$. Denoted the data as $Y_{1_{t}}$.

\section{c Part $(k+1)$ :}

The $(k+1)$ st part is the data from the $k$ th intervention until the end of data analysis based on as many as $n_{k_{t}}$ time periods, i.e. $t=T_{k}, T_{k}+1, T_{k}+2, \ldots, n$. Denote these data as $Y_{k_{t}}$.

The Second Procedure:

Modeling of the first intervention

a Step 1:

(1) Apply Box-Jenkins procedure to get a review ARIMA model building for time series data before the first intervention $Y_{0_{t}}$ occurs. It can be simply written as follow:

$$
Y_{0_{t}}=\frac{\theta_{q}(B) \Theta_{Q}\left(B^{S}\right)}{\varphi_{p}(B) \Phi_{P}\left(B^{S}\right)(1-B)^{d}\left(1-B^{S}\right)^{D}} a_{t} .
$$

(2) Forecast Part 2 dataset $Y_{1_{t}}$ using the best of ARIMA model. In this step, the forecasted data are $\hat{Y}_{T_{1}}, \hat{Y}_{T_{1}+1}, \ldots, \hat{Y}_{T_{1}+n_{1}-1}$.

b Step 2:

(1) Calculate the response values of the first intervention or $Y_{1_{t}}^{*}$. These are the residuals of the data for time periods $t=T_{1}, T_{1}+1, T_{1}+2, \ldots, T_{2}-1$, based on the forecasting of the ARIMA model in the first step. This step produces response values of the first intervention, i.e. $Y_{T_{1}}^{*}, Y_{T_{1}+1}^{*}, \ldots, Y_{T_{2}-1}^{*}$.

(2) Determination of set order $b_{1}, s_{1}, r_{1}$ from the first intervention by using the plot of response values $Y_{T_{1}}^{*}, Y_{T_{1}+1}^{*}, \ldots, Y_{T_{2}-1}^{*}$ and a confidence interval of width, i.e. $\pm 3 \hat{\sigma}_{a_{0}}$, where $\hat{\sigma}_{a_{0}}$ is Root Mean Square Error (RMSE) of the previous ARIMA model.

(3) This interval is based on the determination of control chart bounds during statistical quality control for detecting outlier observations.

c Step 3:

(1) Estimate the parameter and test the significance for the first intervention model.

(2) Conduct a diagnostic check to examine the residual assumption, i.e. white noise and normality distribution. In this step, the first input intervention model is

$$
Y_{t}=\frac{\omega_{s_{1}}(B) B^{b_{1}}}{\delta_{r_{1}}(B)} \xi_{1, t}+\frac{\theta_{q}(B) \Theta_{Q}\left(B^{S}\right)}{\varphi_{p}(B) \Phi_{P}\left(B^{S}\right)(1-B)^{d}\left(1-B^{S}\right)^{D}} a_{t} .
$$

The Third Prosedure:

Modeling of the $m$ th Intervention Model, where $m=2$, $3, \ldots, k$

\section{a Step 1:}

Forecast data $(m+1) \quad Y_{m_{t}}$ based on the $(m-1)$ st intervention model. In this step, we obtain the forecasted values from the $(m-1)$ st intervention model, i.e. $\hat{Y}_{T_{m}}, \hat{Y}_{T_{m}+1}, \ldots, \hat{Y}_{T_{m}+n_{m}-1}$.

b Step 2:

(1) Calculate the $m$ th intervention responses $Y_{m_{t}}^{*}$, which is the residual of the data periods for $t=T_{m}, T_{m}+1, \ldots, T_{m+1}-1$, This is based on the forecasting of the $(m-1)$ st intervention model. These response values are denoted as

$$
Y_{T_{m}}^{*}, Y_{T_{m}+1}^{*}, \ldots, Y_{T_{m+1}-1}^{*} \text {. }
$$

(2) Identify presume orders $b_{m}, s_{m}, r_{m}$ from the $(m-1)$ th intervention model from the plot of response values $Y_{T_{m}}^{*}, Y_{T_{m}+1}^{*}, \ldots, Y_{T_{m+1}-1}^{*}$, and the confidence interval of width $\pm 3 \hat{\sigma}_{a_{m-1}}$.

c Step 3:

(1) Perform parameter estimates as a measure seeking the best or most efficient estimates for the parameters in the model and test of significance as in the comparative evaluation of the $m$ th intervention models.

(2) Checks diagnostic to evaluate and/or examine the suitability of residual assumption that if residual eligible white noise and normally distributed. This step 
can also be tested against the residual is a white noise process can be done individually or jointly. Testing can be done individually if known distribution of the estimated residual, which is generally near normal with mean zero. While testing the model all together is by Ljung-Box. The result of this step is

$$
Y_{t}=\sum_{j=1}^{m} \frac{\omega_{s_{j}}(B) B^{b_{j}}}{\delta_{r_{j}}(B)} \xi_{j t}+N_{t}
$$

This procedure is done iteratively until the last $k$ th intervention. As a result of these steps, eventually we obtain the following multi-input intervention model as

$$
Y_{t}=\sum_{j=1}^{k} \frac{\omega_{s_{j}}(B) B^{b_{j}}}{\delta_{r_{j}}(B)} \xi_{j, t}+\frac{\theta_{q}(B) \Theta_{Q}\left(B^{S}\right)}{\varphi_{p}(B) \Phi_{P}\left(B^{S}\right)(1-B)^{d}\left(1-B^{S}\right)^{D}} a_{t}
$$

Based on the procedures for establishing multi-input intervention model in Section 4, the number of passengers carried data modeling types of domestic flights in Pekanbaru
Airport with the following steps.

\section{Results and Discussion}

\subsection{Pre-intervention Model Results}

This section presents the results of the Box-Jenkins procedure $[5$, p. $93 ; 41$, p. $101 ; 26$, p. 231] utilized for this research which includes the identification, parameter estimation, diagnostic checking and forecasting to find the best ARIMA model before the first intervention, i.e. the smog disaster since June 2013.

The identification step shows that the data are not stationary both in variance and mean. In this case, a homogeneous nonstationary time series can be reduced to a stationary time series by taking a proper degree of differencing [39, p. 71]. Stationary data on the mean obtained through differencing before the first intervention after regular and seasonal differencing $(d=1, D=1$ and $S=12)$. Based on this Box-Cox transformation [39, p. 85], a natural log is employed to cause the variance data to be stationary as shown in Figure 3.

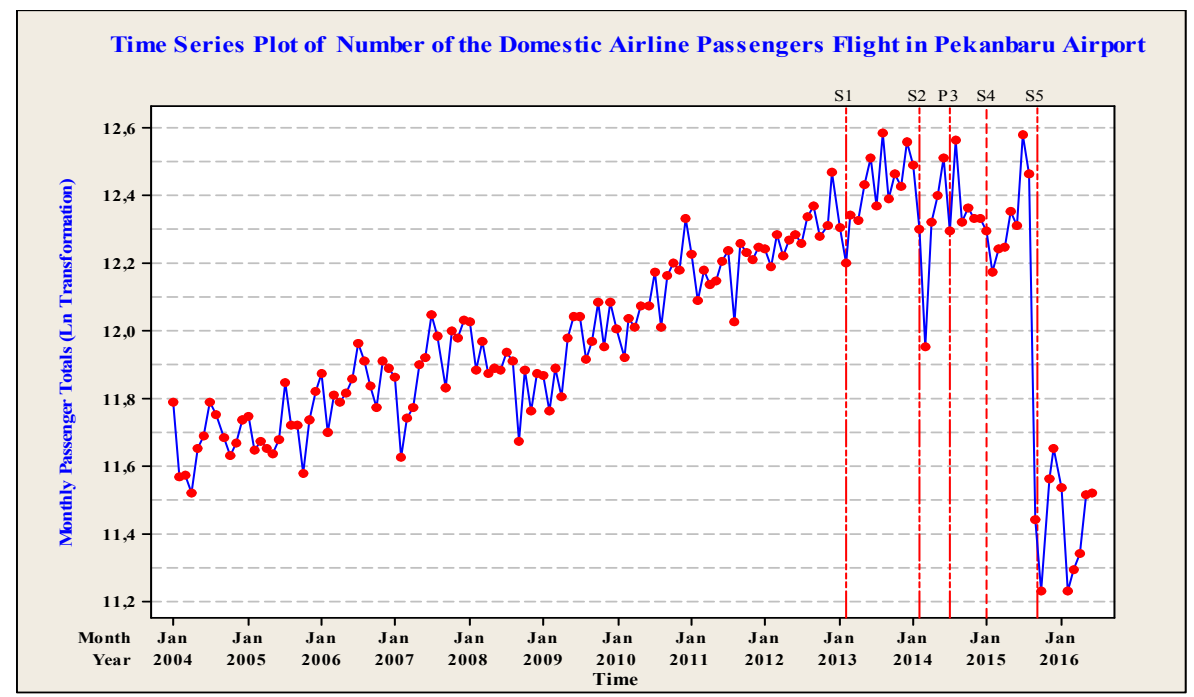

Figure 3. Natural log (In) Transformation of the Monthly Types of the Domestic Airline Passenger in Pekanbaru Airport from January 2004 - December 2016.

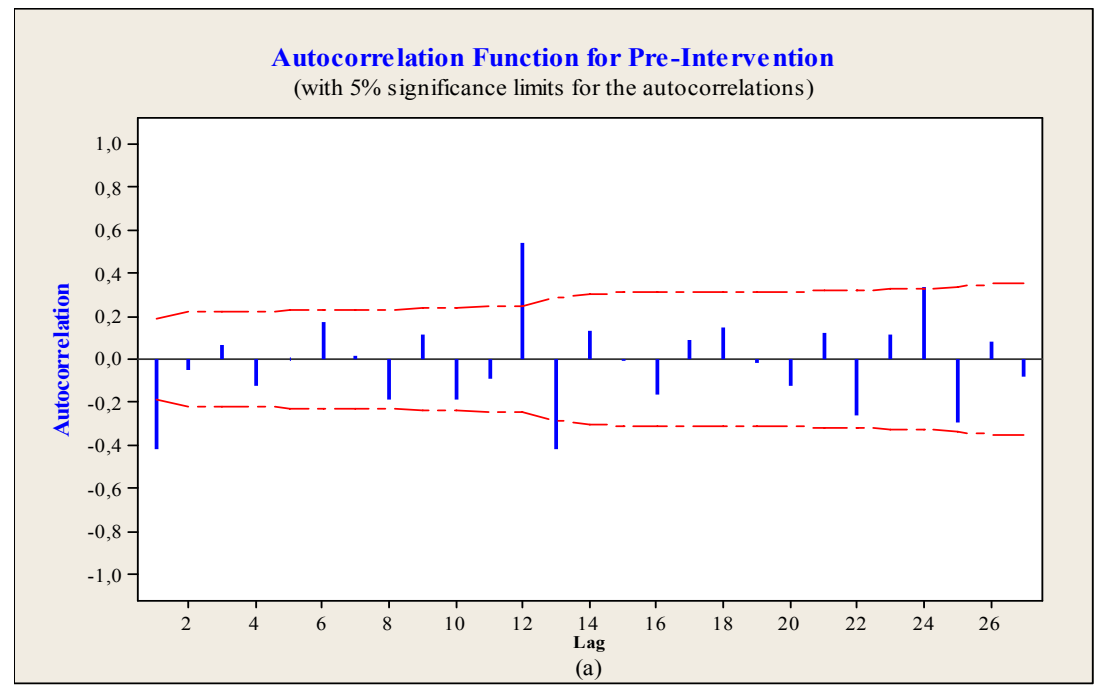




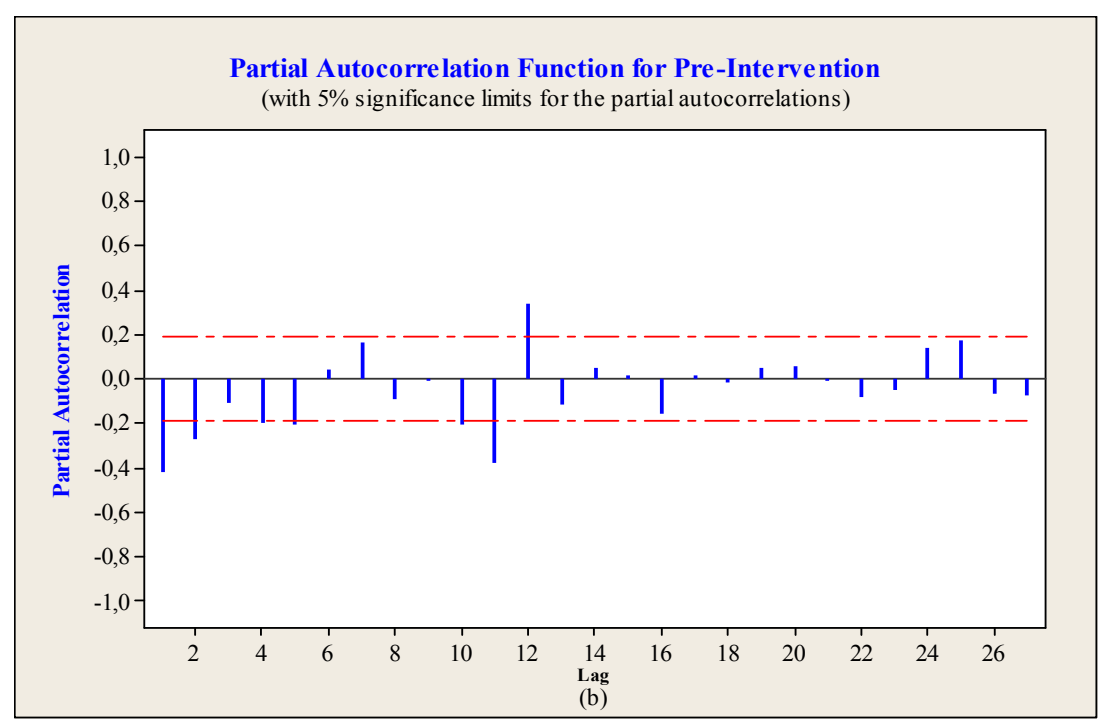

Figure 4. (a) Plot of ACF and (b) PACF of the Stationary Data before the First Intervention after Regular and Seasonal Differencing $(d=1, D=1$ and $S=$ 12).

A realization of this model with its sample autocorrelation function is given in Figure 4. A visual inspection reveals that the mean and variance remains stable while there are some short runs where successive observations tend to follow each other for very brief durations, suggesting that there is indeed some negative autocorrelation as confirmed by the sample ACF plot. The ACF plot of before the first intervention data show that ACF at lag 1 and lag 12 are significantly different with zero or they are greater than the confidence interval of ACF. There are several non seasonal lags (lag 1,2,.., 8) and the ACF tends to be cut off after lag 1 whereas PACF diminishes dies down. On the other hand, ACF and PACF at seasonal lags $(\operatorname{lag} 12,24, \ldots)$ tend to cut off after lag 12 . Hence, there are 2 possible appropriate orders of this ARIMA model, i.e. $(0,1,1)(0,1,2)^{12}$ and $(0,1,1)(0,1,1)^{12}$.

Table 3 shows the results of the parameter estimation, parameter significance test, and diagnostic checking. From this table, we know that both models are appropriate as a means for forecasting the monthly types of the domestic airline passenger in Pekanbaru airport before the first intervention.

Table 3. Results of Parameter Estimation, Parameter Significance Test and Diagnostic Checking.

\begin{tabular}{|c|c|c|c|c|}
\hline \multicolumn{5}{|c|}{ Final Estimates of Parameters } \\
\hline Type & Coef & SE Coef & $\mathbf{T}$ & $\mathbf{P}$ \\
\hline MA 1 & 0,6072 & 0,0826 & 7,35 & 0,000 \\
\hline SMA 12 & 0,7583 & 0,0937 & 8,09 & 0,000 \\
\hline Constant & 183,0 & 151,6 & 1,21 & 0,230 \\
\hline Differencing & 1 regular & 1 seasonal of order 12 & & \\
\hline Number of observations & Original series 109 & after differencing 96 & & \\
\hline Residuals & $\mathrm{SS}=12663716473$ & (backforecasts excluded) & $\mathrm{MS}=136168994$ & $\mathrm{DF}=93$ \\
\hline \multicolumn{5}{|c|}{ Modified Box-Pierce (Ljung-Box) Chi-Square statistic } \\
\hline Lag & 12 & 24 & 36 & 48 \\
\hline Chi-Square & 14,6 & 42,2 & 70,2 & 85,0 \\
\hline $\mathrm{DF}$ & 9 & 21 & 33 & 45 \\
\hline P-Value & 0,104 & 0,004 & 0,000 & 0,000 \\
\hline
\end{tabular}

Completely, the best ARIMA of pre-intervention model for this case can be written as

$$
\ln Y_{t}=\frac{(1-0,6072 B)\left(1-0,7583 B^{12}\right)}{(1-B)\left(1-B^{12}\right)} a_{t}
$$

\subsection{The First Intervention Model Results}

This section presents the results of the intervention model by illustrating the impact of the first step function, namely the smog disaster from February 2013 until December 2013 or at the time $t=110,111, \ldots, 121$. Mathematically, the first intervention type of step function of a deterministic (dummy) intervention indicator is written as

$$
\xi_{t}=S_{1, t}^{(110)}=\left\{\begin{array}{cc}
0, & t \leq 109 \\
1, & t=110,111, \cdots, 121 .
\end{array}\right.
$$

The first step in this model is to determine the order $b_{1}, r_{1}$ and $s_{1}$ for the first step function intervention model [39, p. 324; 41, p. 360]. In this work, Figure 5 illustrates a chart of the residuals to determine the pattern of orders for the first intervention. 


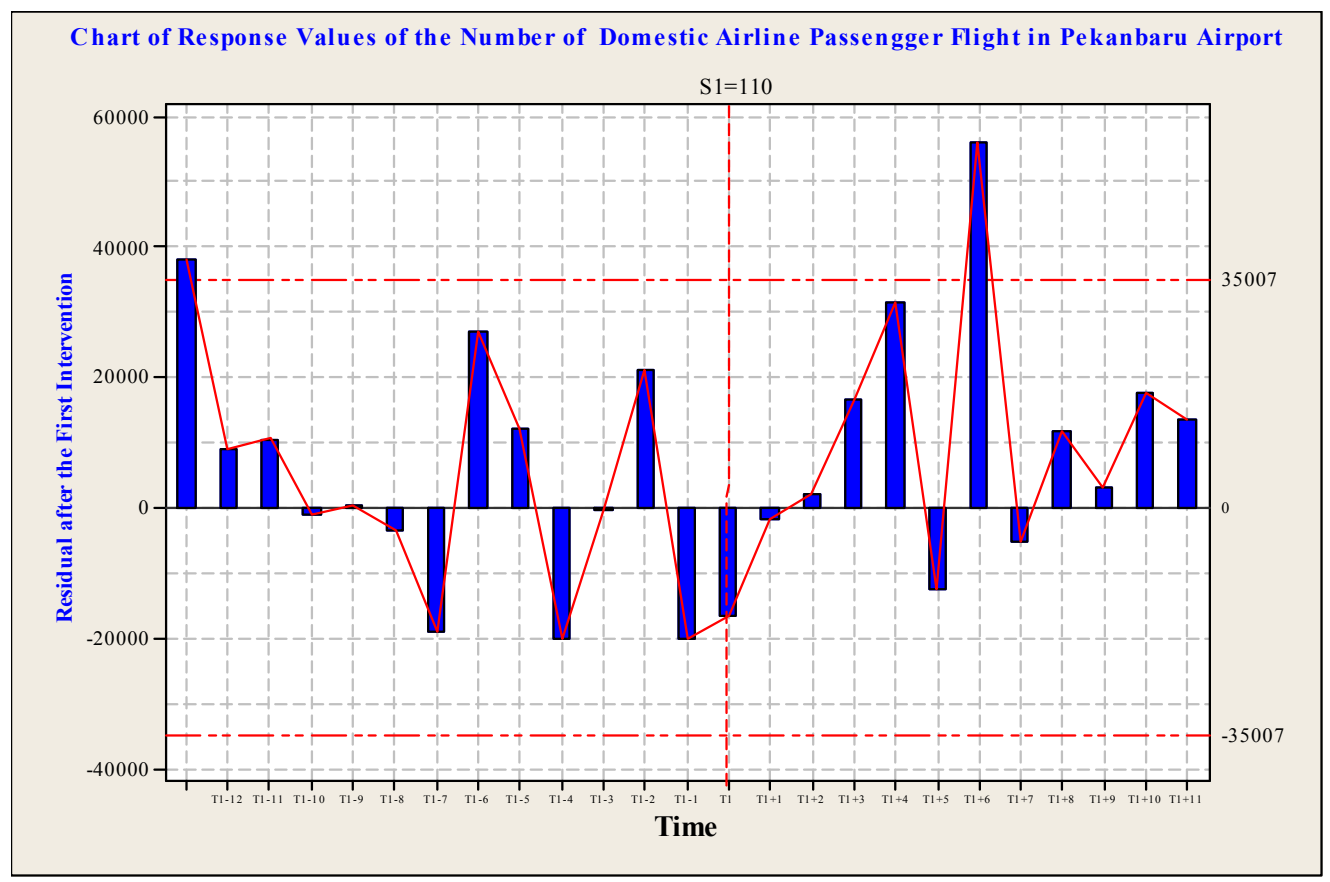

Figure 5. Response values of the Domestic Airline Passenger Flight in Pekanbaru Airport.

Based on the Figure 5, we can see that the response values at time $T_{1}, T_{1}+1, \ldots, T_{1}+5$ have less absolute values than the confidence interval. This graph also illustrates that only the values at $T_{1}+6$ is close to the lower confidence interval. Thus, there is not possible set of order for the first step function intervention model. Parameter estimation and significance tests show that this model order yields significant parameters from this first intervention. Table 4 presents the Minitab output based on the first intervention model.

Table 4. Results of Parameter Estimation, Parameter Significance Test and Diagnostic Checking.

\begin{tabular}{|c|c|c|c|c|}
\hline \multicolumn{5}{|c|}{ Final Estimates of Parameters } \\
\hline Type & Coef & SE Coef & $\mathbf{T}$ & $\mathbf{P}$ \\
\hline MA 1 & 0,6125 & 0,0831 & 7,37 & 0,000 \\
\hline SMA 12 & 0,7964 & 0,0916 & 8,70 & 0,000 \\
\hline Constant & 145,3 & 134,8 & 1,08 & 0,284 \\
\hline Differencing & 1 regular, & 1 seasonal of order 12 & & \\
\hline Number of observations & Original series 109 & after differencing 96 & & \\
\hline Residuals & $\mathrm{SS}=12772941832$ & (backforecasts excluded) & $\mathrm{MS}=135882360$ & $\mathrm{DF}=94$ \\
\hline \multicolumn{5}{|c|}{ Modified Box-Pierce (Ljung-Box) Chi-Square statistic } \\
\hline Lag & 12 & 24 & 36 & 48 \\
\hline Chi-Square & 14,4 & 42,5 & 69,5 & 87,6 \\
\hline DF & 9 & 21 & 33 & 45 \\
\hline P-Value & 0,108 & 0,004 & 0,000 & 0,000 \\
\hline
\end{tabular}

Based on the result parameter estimation and significance tests show that both sets of the model orders yield significant parameters and residuals that satisfy the white noise and normal distribution assumptions. An intervention model for the number of after the first step function intervention and prior to the second step function can be written as

$$
\ln Y_{t}^{(1)}=\frac{(1-0,6125 B)\left(1-0,7964 B^{12}\right)}{(1-B)\left(1-B^{12}\right)} a_{t}
$$

\subsection{Results from the Second Intervention Model}

After modeling the first intervention based on the intervention model due to the disaster smog, furthermore, another analysis of the second step function intervention is conducted. This is based on February 2014 at which is equated with $t=T_{2}=122$. Mathematically, the intervention type of step function is written as

$$
\xi_{t}^{(T)}=S_{2, t}^{(122)}=\left\{\begin{array}{cc}
0, & t \leq 121 \\
1, & t=122,123, \cdots, 126 .
\end{array}\right.
$$

As explained above the forming of intervention model. The first step in this modeling is to determine the order $b_{2}, s_{2}$ and $r_{2}$ for the second step function intervention model. This is done to determine the order of the intervention model and to explain the decrease in the number types of the domestic airline passenger flight in Pekanbaru airport. 


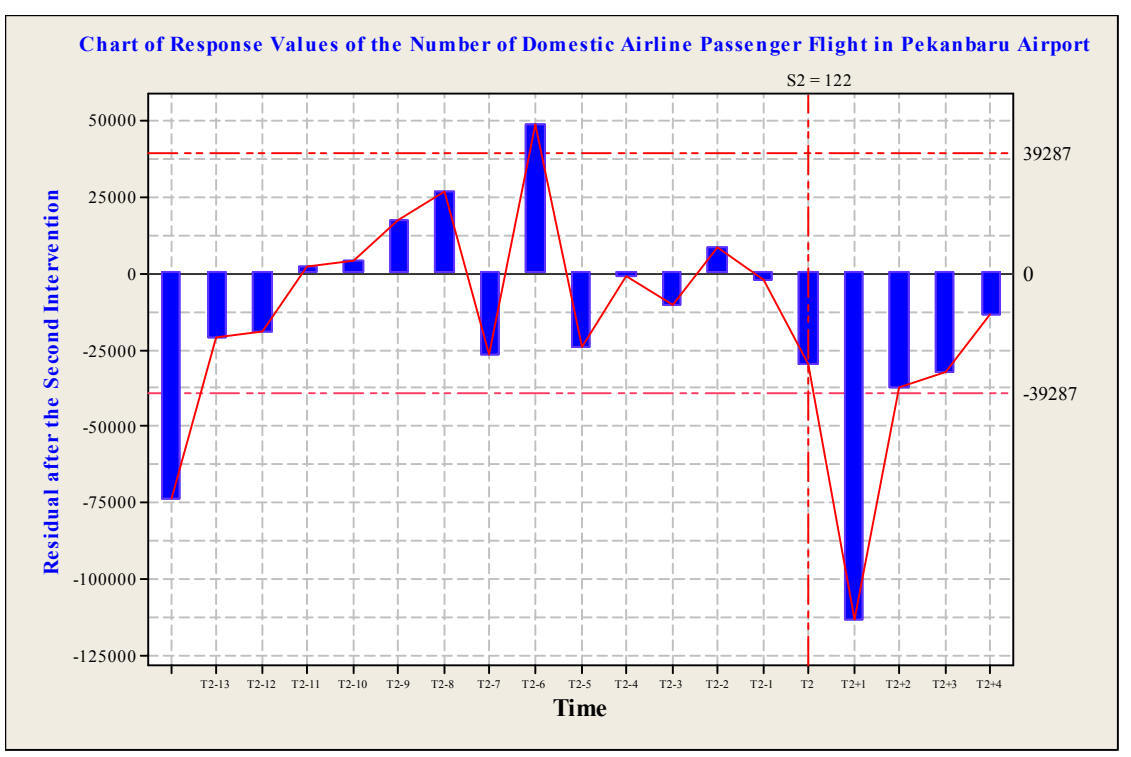

Figure 6. Response values of the Domestic Airline Passenger Flight in Pekanbaru Airport.

The output in Figure 6, we can see that the response values at time $T_{2}, T_{2}+2, T_{2}+3$ and $T_{2}+4$ have less absolute value than the confidence interval. This graph also illustrates that only the response values at time $T_{2}+1$ (March 2014) is close to the confidence intervals. Thus, there is 1 appropriate presume order of the second step function intervention model, i.e. $b_{2}=1, s_{2}=2$ and $r_{2}=0$. Parameter estimation and significance tests show that this model order yields significant parameters from this second intervention. Table 5 presents the SAS output based on the second step function intervention.

Table 5. Results of Parameter Estimation, Parameter Significance Test and Diagnostic Checking.

\begin{tabular}{llll}
\hline Estimasi Parameter & $\mathbf{t}_{\text {hitung }}$ & $\mathbf{p}_{\text {value }}$ & Type of significant \\
\hline$\omega_{0_{2}}=13092.3$ & 1,08 & 0.0010 & significant \\
$\omega_{1_{2}}=-154081.1$ & 1,31 & 0.1931 & significant \\
$\omega_{2_{2}}=-15.76$ & $-15,76$ & 0.0001 & significant \\
\hline
\end{tabular}

Table 6. Results of Parameter Estimation, Parameter Significance Test and Diagnostic Checking.

\begin{tabular}{lllll}
\hline Final Estimates of Parameters & & & & \\
\hline Type & Coef & SE Coef & T & P \\
\hline MA 1 & 0,7146 & 0,0692 & 10,32 & 0,000 \\
SMA 12 & 0,8456 & 0,0843 & 2,03 & 0,000 \\
Constant & 195,97 & 90,70 & 0,033 \\
Differencing & 1 regular, & 1 seasonal of order 109 & & \\
Number of observations & Original series 122 & after differencing 96 & & DF $=106$ \\
Residuals & SS = 18549961248 & (backforecasts excluded) & MS $=174999634$ & \\
Modified Box-Pierce (Ljung-Box) Chi-Square statistic & & & 48 \\
Lag & 12 & 24 & 70,4 & 85,8 \\
Chi-Square & 16,2 & 42,0 & 33 & 45 \\
DF & 9 & 21 & 0,000 & 0,000 \\
P-Value & 0,062 & 0,004 & & \\
\hline
\end{tabular}

Based on the results listed in Table 5, an intervention model for the number types of the domestic airline passenger flight in Pekanbaru airport after the first step function intervention and prior to the third step function intervention can be written as

$\ln Y_{t}^{(2)}=\left[\left(13092.3 S_{t-1}-154081.1 S_{t-2}-15.76 S_{t-3}\right)\right]+N_{t}$

where

$$
N_{t}=\frac{(1-0,7146 B)\left(1-0,8456 B^{12}\right)}{(1-B)\left(1-B^{12}\right)} a_{t} .
$$

\subsection{Results from the Third Intervention Model}

The final analysis of the third pulse intervention based on national election event. The best of intervention model for the national election as a political year, which took event on July 2014 is equated with $t=T_{3}=127$. Mathematically, the pulse function in this intervention could be written as

$$
\xi_{t}^{(T)}=P_{3, t}^{(127)}= \begin{cases}0, & t \neq 127 \\ 1, & t=127 .\end{cases}
$$

As described in the previous section, the first step in this modeling is to determine the order $b_{3}, r_{3}$ and $s_{3}$ for the third 
pulse function intervention model. This is done to determine the order of the intervention model and to explain the decrease in the number monthly types of the domestic airline passenger in Pekanbaru airport due to the national election and to determine the order of intervention. A residual chart is as in Figure 7 is used to show this step.

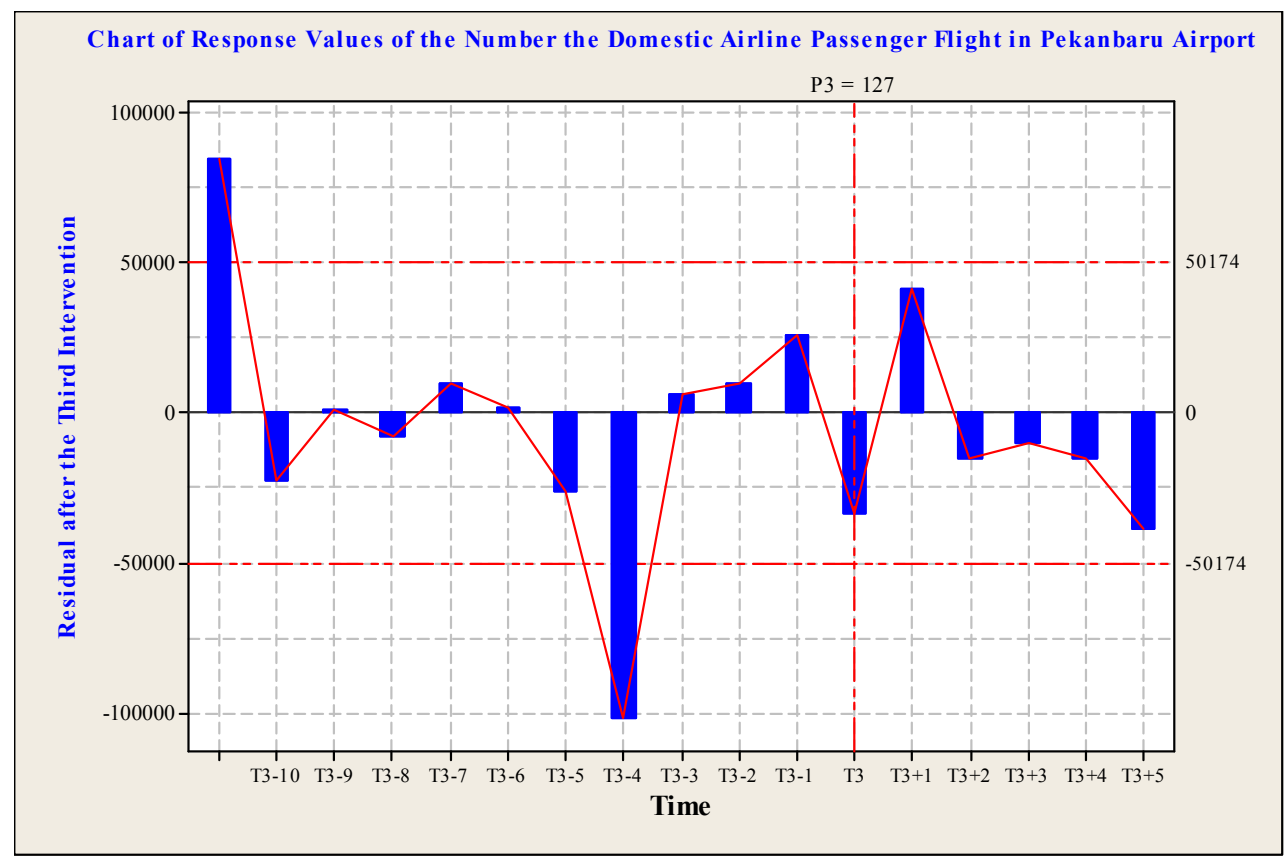

Figure 7. Response values of the Domestic Airline Passenger Flight in Pekanbaru Airport.

From Figure 7 shows a chart of the residuals to determine the order of $b_{3}, s_{3}$, and $r_{3}$ for the third intervention model based on the national election and we can see the response values at time $T_{3}, T_{3}+1, T_{3}+2, \ldots$, $T_{3}+5$ have less absolute values than the confidence interval. This graph also illustrates that there is not values is close to the lower confidence interval. Thus, there is not possible set of order for the third pulse function intervention model. Parameter estimation and significance tests show that this model ARIMA yields significant parameters from this third intervention. After we estimated the parameters of each identified model, the estimated model should be tested to verify the assumption of residual.

Table 7. Results of Parameter Estimation, Parameter Significance Test and Diagnostic Checking.

\begin{tabular}{|c|c|c|c|c|}
\hline \multicolumn{5}{|c|}{ Final Estimates of Parameters } \\
\hline Type & Coef & SE Coef & $\mathbf{T}$ & $\mathbf{P}$ \\
\hline MA 1 & 0,6941 & 0,0702 & 9,89 & 0,000 \\
\hline SMA 12 & 0,7976 & 0,1055 & 7,56 & 0,000 \\
\hline Constant & 58,5 & 134,1 & 0,44 & 0,663 \\
\hline Differencing & 1 regular, & 1 seasonal of order 109 & & \\
\hline Number of observations & Original series 122 & after differencing 96 & & \\
\hline Residuals & $\mathrm{SS}=31049358608$ & (backforecasts excluded) & MS $=279723951$ & $\mathrm{DF}=111$ \\
\hline \multicolumn{5}{|c|}{ Modified Box-Pierce (Ljung-Box) Chi-Square statistic } \\
\hline Lag & 12 & 24 & 36 & 48 \\
\hline Chi-Square & 16,4 & 27,4 & 42,8 & 50,2 \\
\hline DF & 9 & 21 & 33 & 45 \\
\hline P-Value & 0,059 & 0,159 & 0,118 & 0,276 \\
\hline
\end{tabular}

The SAS output shown in Table 6 shows that the final multi-input intervention model for the number of the domestic airline passengers in Pekanbaru airport after the third pulse intervention function can be written as

$$
\ln \hat{Y}_{t}^{(3)}=\frac{(1-0,6941 B)\left(1-0,7976 B^{12}\right)}{(1-B)\left(1-B^{12}\right)} a_{t} .
$$

\subsection{Results from the Fourth Intervention Model}

After modeling the third intervention based on the intervention model due to the disaster smog, another analysis of the fourth step function intervention was conducted. This was based on January 2015 at which is equated with $t=T_{4}=$ 133. Mathematically, the intervention type of step function is written as 


$$
\xi_{t}^{(T)}=S_{4, t}^{(133)}=\left\{\begin{array}{cc}
0, & t \leq 132 \\
1, & t=133,134, \cdots, 140 .
\end{array}\right.
$$

The first step in this modeling is to determine the order $b_{4}$, $s_{4}$ and $r_{4}$ for the third step function intervention model. This is done to determine the order of the intervention model and to explain the decrease in the number of the number types of the domestic airline passenger flight on Riau Province via Sultan Syarif Kasim II International airport due to the disaster smog.

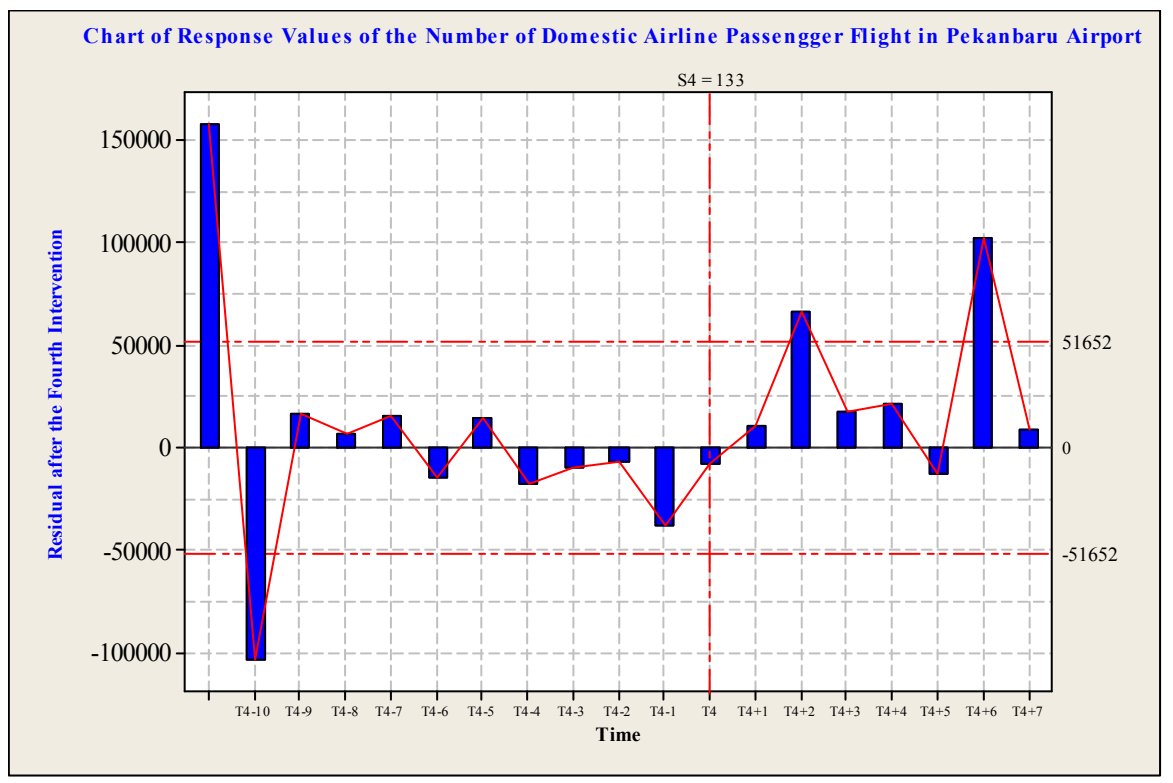

Figure 8. Response values of the Domestic Airline Passenger Flight in Pekanbaru Airport.

Table 8. Results of Parameter Estimation, Parameter Significance Test and Diagnostic Checking.

\begin{tabular}{lllll}
\hline Final Estimates of Parameters & & & & T \\
\hline Type & Coef & SE Coef & 7,26 & P \\
\hline MA 1 & 0,5788 & 0,0797 & 1,92 & 0,000 \\
SMA 12 & 0,2401 & 0,1253 & $-0,50$ & 0,058 \\
Constant & $-253,7$ & 512,4 & & 0,621 \\
Differencing & 1 regular & 1 seasonal of order 12 & & \\
Number of observations & Original series 133 & after differencing 120 & & MS $=296437086$ \\
Residuals & SS = 34683139057 & (backforecasts excluded) & & DF $=117$ \\
Modified Box-Pierce (Ljung-Box) Chi-Square statistic & & 36 & 48 \\
Lag & 12 & 24 & 32,2 & 37,9 \\
Chi-Square & 7,9 & 21,4 & 33 & 45 \\
DF & 9 & 21 & 0,507 & 0,766 \\
P-Value & 0,540 & 0,432 & & \\
\hline
\end{tabular}

Figure 8 shows that the response values at time $T_{4}+2$ and $T_{4}+6$ have greater absolute values than the confidence intervals. This means that there are 2 possible sets of orders for the fourth step function intervention model, i.e. the first set order is $b_{4}=2, s_{4}=0, r_{4}=1$ and the second is $b_{4}=2, s_{4}=$
$3, r_{4}=0$. Parameter estimation and significance tests show that both sets of the model orders yield significant parameters and residuals that satisfy the white noise and Normal distribution assumptions.

Table 9. Results of Parameter Estimation, Parameter Significance Test and Diagnostic Checking.

\begin{tabular}{llll}
\hline Parameter Estimation & $\boldsymbol{t}_{\text {value }}$ & $\boldsymbol{p}_{\text {value }}$ & Type of significant \\
\hline$\theta_{1}=0,5788$ & 7,26 & 0,000 & Significant \\
$\Theta_{1}=0,2401$ & 1,92 & 0,058 & Significant \\
$\omega_{0_{4}}=-11.129,1$ & -1.01 & 0.3137 & Significant \\
$\omega_{1_{4}}=-158.270,5$ & -15.16 & $<.0001$ & Significant \\
$\omega_{2_{4}}=68.114,3$ & 4,44 & $<.0001$ & Significant \\
$\omega_{3_{4}}=-67.088,6$ & -3.85 & 0.0002 & Significant \\
\hline
\end{tabular}


Based on the results in Table 7, an intervention model for the number types of the domestic airline passenger flight in Pekanbaru airport after the fourth step function intervention and prior to the fifth step function intervention can be written as

$$
\ln Y_{t}^{(4)}=\left(-11.129 S_{4, t-9}+158.27 S_{4, t-10}-68.144 S_{4, t-11}+67.088 S_{4, t-12}\right)+N_{t}
$$

where

$$
N_{t}=\frac{(1-0,5788 B)\left(1-0,2401 B^{12}\right)}{(1-B)\left(1-B^{12}\right)} a_{t}
$$

The calculations show that the disaster smog resulted in decrease the number of domestic passengers flying air passing through the Sultan Syarif Kasim II Pekanbaru airport per month of 193290 passengers. This decline has occurred since the incidence of fire disaster until prior to the fifth intervention, which began in February 2015 and fluctuated until August 2015.

\subsection{Results from the Fifth Intervention Model}

The final analysis of the fifth step intervention function based on the disaster smog 2015 which took place on September 2015 or at the time $t=T_{5}=141$ until $t=T_{5}=150$. Mathematically, the intervention type of step function is written as

$$
\xi_{t}^{(T)}=S_{5, t}^{(141)}=\left\{\begin{array}{cc}
0, & t \leq 140 \\
1, & t=141,142, \cdots, 150 .
\end{array}\right.
$$

The first step in this analysis is to determine the order of the 5 th intervention model. Figure 9 shows a chart of the residuals to determine the order of $b_{5}, s_{5}$ and $r_{5}$ used in the intervention model. The residuals will be used to model the decrease of the number types of the domestic airline passenger flight in Pekanbaru airport via Sultan Syarif Kasim II International airport due to the disaster smog.

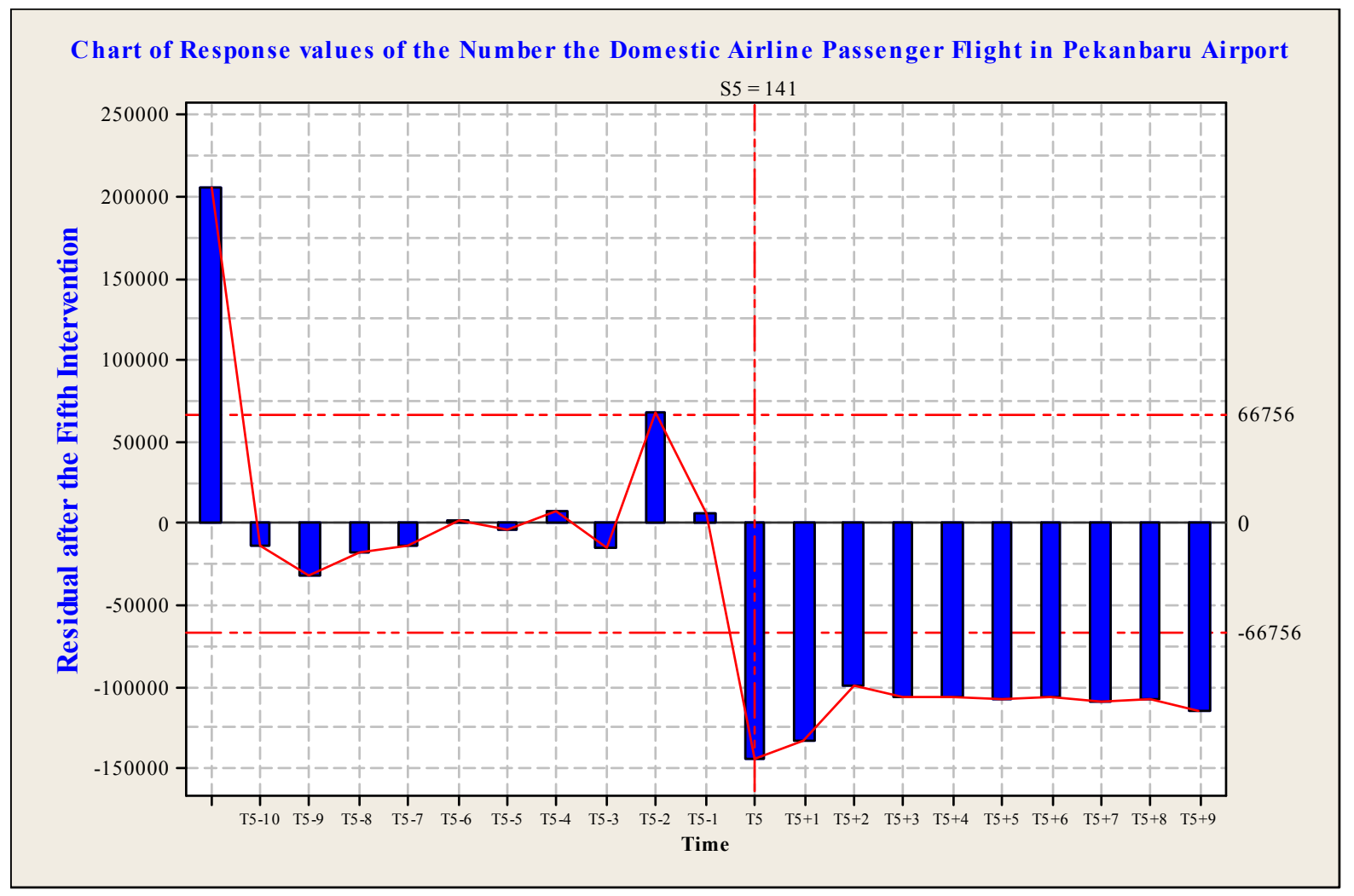

Figure 9. Response values of the Domestic Airline Passenger Flight in Pekanbaru Airport.

Based on the results a chart of the residuals in Figure 9, this means that there are 2 possible sets of order for the fifth step function intervention model, the first set order is $b_{5}=1$, $s_{5}=(1,2), r_{5}=0$ and the second is $b_{5}=0, s_{5}=0, r_{5}=0$ due to a decrease in residual patterns tend to form a straight line, which indicates a constant effect, parameter estimation and significance tests show that both set of the model orders yield significant parameters and residuals that satisfy the white noise and normal distribution assumptions. The comparison of SBC criteria shows that the second model yields better result than the first. The results in Table 8 are shown using the SAS output. 
Table 10. Results of Parameter Estimation, Parameter Significance and Diagnostic Checking.

\begin{tabular}{lllll}
\hline \multicolumn{2}{l}{ Final Estimates of Parameters } & & & T \\
\hline Type & Coef & SE Coef & P & \\
\hline MA 1 & 0,7640 & 0,0660 & 11,58 & 0,000 \\
SMA 12 & 0,8148 & 0,0937 & 8,70 & 0,000 \\
Constant & $-122,6$ & 124,7 & $-0,98$ & 0,328 \\
Differencing: & 1 regular & 1 seasonal of order 12 & & \\
Number of observations & Original series141 & after differencing128 & & DF=125 \\
Residuals: & SS=61894852129 & (backforecasts excluded) & MS $=495158817$ & \\
Modified Box-Pierce (Ljung-Box) Chi-Square statistic & & & 48 \\
Lag & 12 & 24 & 36 & 51,6 \\
Chi-Square & 5,3 & 24,1 & 44,2 & 45 \\
DF & 9 & 21 & 33 & 0,231 \\
P-Value & 0,812 & 0,288 & 0,092 & \\
\hline
\end{tabular}

Table 11. Results of Parameter Estimation, Parameter Significance test and Diagnostic Checking.

\begin{tabular}{llll}
\hline Parameter Estimation & $\boldsymbol{t}_{\text {value }}$ & $\boldsymbol{p}_{\text {value }}$ & Type of significant \\
\hline $\boldsymbol{\theta}_{1}=0,7640$ & 11,58 & 0,00 & Significant \\
$\Theta_{1}=0,8148$ & 8,70 & 0,00 & Significant \\
$\omega_{0_{1}}=-161.255,4$ & -14.70 & $<.0001$ & Significant \\
\hline
\end{tabular}

In this case, the intervention model for the number types of the domestic airline passenger flight in Pekanbaru airport via Sultan Syarif Kasim II International airport after the 1st, 2nd, 3rd, 4th and 5 th step intervention function can be written as

$$
\ln Y_{t}^{(5)}=-161.255,4 S_{5, t-9}+\frac{(1-0,7640 B)\left(1-0,8148 B^{12}\right)}{(1-B)\left(1-B^{12}\right)} a_{t}
$$

The effect of the reconstruction and the forecast of the final intervention model as the for transformation data (natural $\log$ ) are presented in Figure 10.

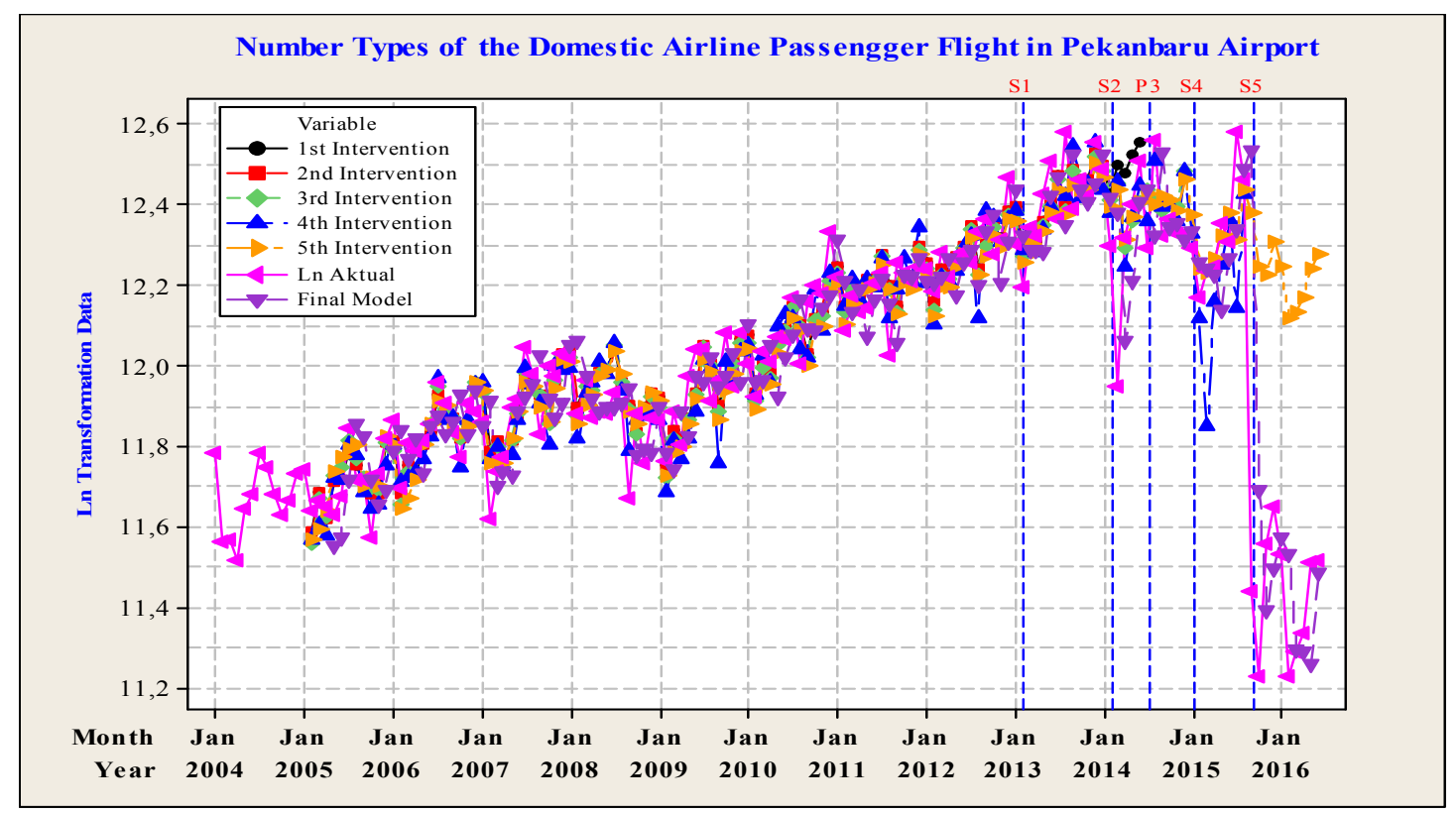

Figure 10. Effect on the Reconstruction and Forecast values of the Domestic Airline Passenger Flight in Pekanbaru Airport.

\section{Evaluating and Monitoring Forecasting Model Performance}

This paper considers how to evaluate the performance of forecasting technique for a particular time series or application. It is important to carefully define the meaning of performance. It is tempting to evaluate performance on the basis of the fit of the forecasting or time series model to historical data.

An evaluation of the impact for each intervention could not be done directly based on the model of equation (28). This has caused the data not in origin scale, so the effect of each intervention could not be directly used as the estimated parameters. The rational for this statement is based on the assumption that the intervention model that we want to 
evaluate is as follows (see Lee et al. [25], and Zhang et al. [42])

$$
Y_{t}=Y_{t}^{*}+n_{t}
$$

where

$Y_{t}=$ The actual data

$Y_{t}^{*}=$ The intervention effect

$n_{t}=$ "Noise" model follows to $\operatorname{ARIMA}(p, d, q)(P, D, Q)^{S}$

for error (data without intervention effect)

Besides that, the next assumption is that the intervention effect follows the simplest model, i.e.

$$
Y_{t}^{*}=\omega_{0} \xi_{t}^{(T)}
$$

where

$\xi_{t}^{(T)}=S_{t}^{(T)}=$ The step function at a certain $T$.

In this case, the effect of the intervention at $t=T$ is

$$
Y_{T}^{*}=Y_{T}-n_{T}=\omega_{0} .
$$

Thus, we could directly use the estimated parameters to measure the impact of an intervention. On the other, we can assume that the variance data is not stationary and we must transform this data by using natural log. So the process can be written as

$$
\tilde{Y}_{t}=\ln Y_{t}
$$

$$
\tilde{Y}_{t}=\tilde{Y}_{t}^{*}+n_{t} .
$$

If it is defined as

$$
\tilde{Y}_{t}^{*}=\omega_{0} S_{t}^{(T)}
$$

then the effect of this intervention at $t=T$ on the transformation data is

$$
\tilde{Y}_{T}^{*}=\tilde{Y}_{T}-n_{T}=\omega_{0} .
$$

Hence, the impact of this intervention on the original data is:

$$
Y_{T}^{*}=e^{\tilde{Y}_{T}^{*}+n_{T}}-e^{n_{T}} \neq e^{\tilde{Y}_{T}^{*}} .
$$

This result shows that the estimated parameters of this intervention model at transformation data could not be interpreted directly due to the magnitude of the effects of an intervention. Therefore, the effect of the intervention on the transformation data at a certain time must be calculated by using the difference between the forecast of this intervention and the pre-intervention models.

Following this, we can transform the data to the original scale to examine the impact and the results of each intervention as shown in Figure 11. Based on this conversion to the original data scale, the impact of the first, second, third, fourth and fifth interventions are summarized in the following sections.

And the intervention model is

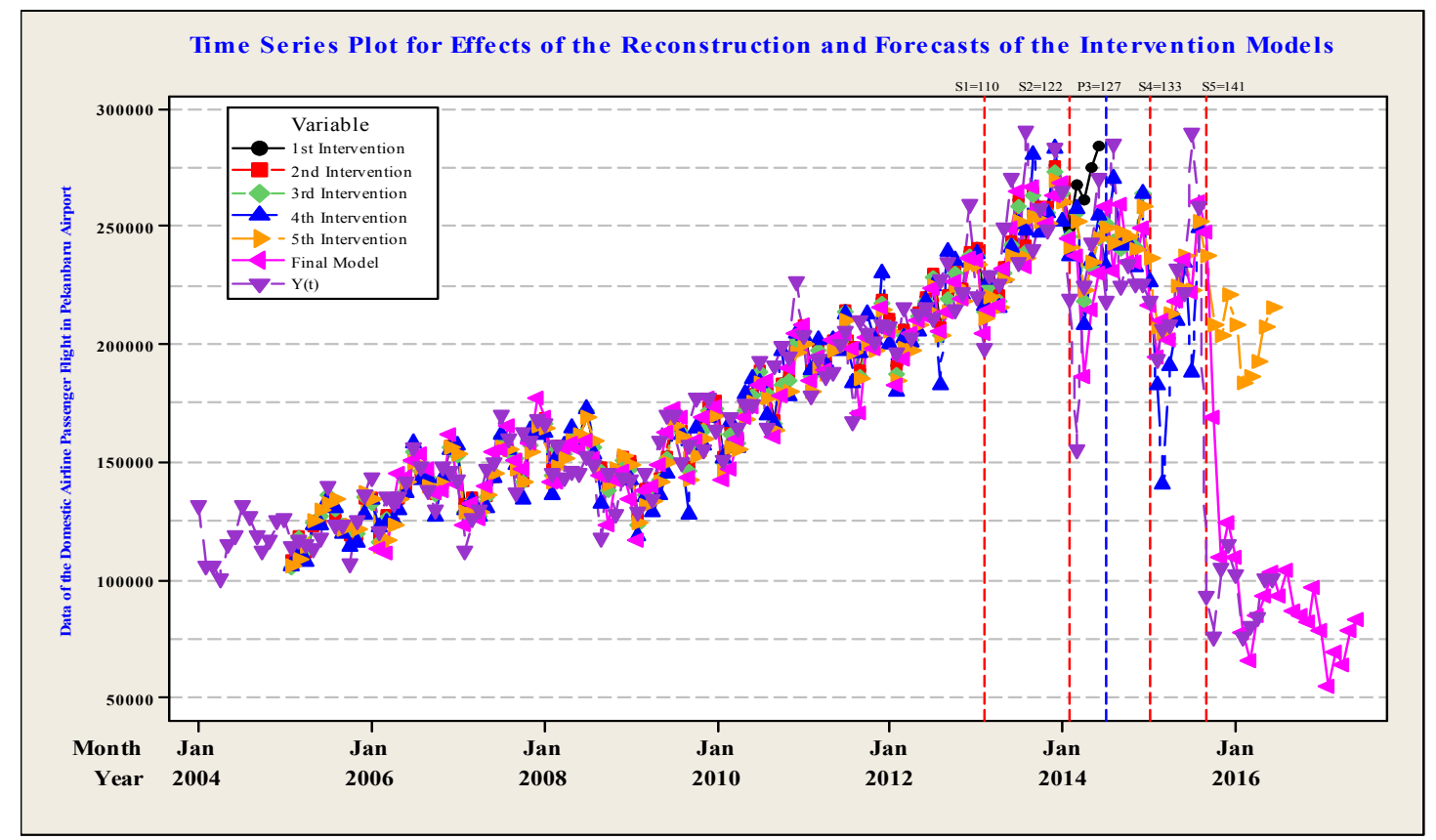

Figure 11. Effects of the Reconstruction and Forecasts of the First, Second, Third, Fourth and Fifth Interventions Models (Original Data).

\section{Conclusions}

In this study, the theoretical and empirical studies on the intervention model were carried out to determine the order of the intervention model. This model includes the derivation of some effect shapes categorized as temporary, gradually or 
permanent effect.

Based on the results of the discussion above, it can be concluded that each model, as a result of their intervention has a constructed forecasting model highly influenced by the phenomenon of external and/or internal factors. The final results of this theoretical study were developed a procedure for establishing an intervention model which includes three main stages of modeling. All the computations involved in this research have been performed by using MINITAB version 16 and SAS.

This paper also shows that the interpretation of an intervention model for transformation data could not be done directly based on estimated model parameters. Further research is needed to understand the precise impact of the interventions on other forms of data transformation.

However, the availability of sophisticated statistical software packages such as Minitab, JMP and SAS makes it possible for the practitioner to consider several different models with various orders and compare them based on the model selection criteria such as AIC, AICC and SIC and residual analysis.

\section{Acknowledgement}

We would like to thank the Sultan Syarif Kasim II International Airport for providing us with the number of passenger types domestic flight data. These supports are gratefully acknowledged.

\section{References}

[1] B. Abraham, Intervention analysis and multiple time series, Biometrika, 1 (1980), 73 - 78.

[2] M. S. Atkins, A Case study on the use of intervention analysis applied to traffic accidents, Journal of the Operational Research Society, 7 (1979), 651 - 659.

[3] P. J. Brockwell and R. A. Davis, Introduction to Time Series and Forecasting, Spinger-Verlag, New York, 1996.

[4] B. L. Bowerman, R. T. O'Connell and A. Koehler, Forecasting, Time Series and Regression: An Applied Approach, 4th Edition, Duxbury Press, Belmont, California, 2004.

[5] G. E. P. Box, G. M. Jenkins and G. C. Reinsel, Time Series Analysis Forecasting and Control, 5th Edition, John Wiley \& Sons, Inc., Hoboken, New Jersey, 2016.

[6] G. E. P. Box and G. C. Tiao, Intervention analysis with applications to economic and environmental problems, Journal of the American Statistical Association, 70 (1975), 70 - 79.

[7] L. Bianchi, W. Gautschi, J. Jarrett and R. C. Hanumara, Improving forecasting for telemarketing centers by ARIMA modeling with intervention, International Journal of Forecasting, 14 (1998), 497 - 504.

[8] M. N. Bhattacharyya and A. P. Layton, Effectiveness of seat belt legislation on the Queensland road toll - an Australian case study in intervention analysis, Journal of the American Statistical Association, 74 (1979), 596 - 603.
[9] N. B. Chang and Y. T. Lin, An analysis of recycling impacts on solid waste generation by time series intervention modeling, Resources, Conservation and Recycling, 19 (1997), $165-186$.

[10] C. Chatfield, Time Series Forecasting, Chapman Hall, London, 2001.

[11] J. D. Cryer and Kung-Sik Chan, Time Series Analysis with Applications in R, 2nd edition, Springer, New York, 2008.

[12] K. Drakos and A. Kutan, Regional effects of terrorism on tourism in three Mediterranean countries. Journal of Conflict Resolution, 47 (2003), 621 - 641.

[13] W. Enders, Applied Econometric Time Series, John Wiley \& Sons, Inc., New York, 1995.

[14] W. Enders, T. Sandler, and J. Cauley, Assessing the impact of terrorist thwarting policies: An intervention time series approach. Defense and Peace Economics, 2 (1990), 1 - 18.

[15] A. Harvey and J. Durbin, The effects of seat belt legislation on British road casualties, Journal of the Royal Statistical Society, Series A, 4 (1986), 187 - 227.

[16] J. D. Hamilton, Time Series Analysis, New Jersey: Princeton University Press, New York, 1994.

[17] M. E. Hilton, The impact of recent changes in California drinking-driving laws on fatal accident levels during the first post intervention Year: An Interrupted time series analysis, Law \& Society Review, 18 (1984), 605 - 627.

[18] U. Helfenstein, The use of transfer function models, intervention analysis and related time series methods in epidemiology, International Journal of Epidemiology, 3 (1991), $808-815$.

[19] Z. Ismail, Suhartono, A. Yahaya and R. Efendi, Intervention model for analyzing the impact of terrorism to the tourism industry, Journal of Mathematics and Statistics, 5 (2009), 322 -329 .

[20] [20]H. Jorquera, W. Palma, and J. Tapia, An intervention analysis of air quality data at Santiago, Chile. Atmospheric Environment, 34 (2000), 4073 - 4084.

[21] Rising Fuel Price, Ministry of Finance of Republic of Indonesia, http://www.kemenkeu.go.id, accessed in May 10th, 2016 at 22.35 PM.

[22] H. Luthkepohl, New Introduction Multiple Time Series Analysis, 2nd Edition, Springer, New York, 2005.

[23] C. Y. Lam, W. H. Ip and C. W. Lau, A business process activity model and performance measurement using a time series ARIMA intervention analysis, Expert Systems with Applications, 36 (2009), 6986 - 6994.

[24] J. Ledolter and K. S. Chan, Evaluating the impact of the 65mph maximum speed limit on Iowa interstates. The American Statistician, 50 (1996), 79 - 85.

[25] M. H. Lee, Suhartono and B. Sanugi, Multi-input intervention model for evaluating the impact of the Asian crisis and the terrorist attacks on tourist arrivals, Matematika, 26 (2010), 83 -106 .

[26] D. C. Montgomery, C. L. Jennings and M. Kulahci, Introduction to Time Series Analysis and Forecasting, John Wiley \& Sons, Inc., New Jersey, 2008. 
[27] J. P. Murry, A. Stam and J. L. Lastovicka, Evaluating an antidrinking and driving advertising campaign with a sample survey and time series intervention analysis, Journal of the American Statistical Association, 2 (1993), 50-56.

[28] A. J. McSweeny, The effects of response cost on the behavior of a million persons: Charging for directory assistance in Cincinnati, Journal of Applied Behavioral Analysis, 2 (1978), $47-51$.

[29] D. C. Montgomery and G. Weatherby, Modeling and Forecasting Time Series Using Transfer Function and Intervention Methods, AIIE Transactions, 12 (1980), 289 307.

[30] S. Makridakis and M. Hibon, The M3-Competition: Result, Conclusions and Implications, International Journal of Forecasting, 16 (2000), 451 - 476.

[31] P. W. Novianti and Suhartono, Modeling of Indonesia consumer price index using multi-input intervention model, Bulletin of Monetary Economics and Banking, 12 (2009), 75 96.

[32] Polusi Asap 2015 (Smoke Pollution), http://www.bmkg.go.id, accessed in April 18th, 2016 at 21.30 PM.

[33] Pemilu 2014 (General Election), http://www.kpu.go.id, accessed in April 18th, 2016 at 22.35 PM.

[34] S. Rezeki, Suhartono and Suyadi, Multi-input intervention model for analyzing the impact of the Asian crisis and the terrorist attacks on tourist arrivals in Bali, Applied Mathematical Sciences, 7 (2013), 6715 - 6727.
[35] R. S. Tsay, Analysis of Financial Time Series, 2nd Edition, John Wiley \& Sons, Inc., New Jersey, 2005.

[36] Tim Pusdatinmas BNPB, Disaster of Information Actual Monthly Edition June 2013, National Disater Relief Agency, p. 4, http:// www.bnpb.go.id, accessed in April 18th, 2016, at hour 21.57 .

[37] A. Valadkhani and A. P. Layton, Quantifying the effect of the GST on inflation in Australia's capital cities: An intervention analysis, Australian Economic Review, 2 (2004), 125 - 138.

[38] H. S. Van der Knoop and F. C. Hooijmans, A multivariate intervention model for the Dutch mint circulation: estimation and Monte Carlo simulation, Journal of Asian Economics, 2 (1989), 179-189.

[39] W. W. S. Wei, Time Series Analysis: Univariate and Multivariate Methods, 2nd Edition, Addison-Wesley Publishing Company, Inc., New York, 2006.

[40] R. E. Wimanda, Price variability and price convergence: evidence from Indonesia, Journal of Asian Economics, 20 (2009), 427 - 442.

[41] R. A. Yaffee and M. McGee, Introduction to time series analysis and forecasting with applications of SAS and SPSS, Academic Press, Inc., San Diego, 2000.

[42] F. Zhang, A. K. Wagner, S. B. Soumerai and D. R. Degnan, Methods for estimating confidence intervals in interrupted time series analysis of health interventions, Journal of Clinical Epidemiology, 62 (2009), 143 - 148. 